\title{
THE STUDY OF PARTIALLY AND FULLY OXIDIZED GRAPHENE OXIDE PREPARED BY GREEN SYNTHESIS FOR WIDE-SCALE FABRICATION
}

\author{
D. A. Fatmawati ${ }^{1}$, Triyono ${ }^{1,}$, W. Trisunaryanti ${ }^{1}$, H. S. Oktaviano ${ }^{2}$, \\ and U. Chasanah ${ }^{1}$ \\ ${ }^{1}$ Department of Chemistry, Faculty of Mathematics and Natural Sciences, Universitas Gadjah \\ Mada, Sekip Utara Bulaksumur, Sleman, D.I. Yogyakarta, 55281, Indonesia \\ ${ }^{2}$ Research \& Technology Center, PT. Pertamina (Persero), Sopo Del Tower A, Floor 51, Jl. \\ Mega Kuningan Barat III, Kawasan Mega Kuningan, Jakarta Selatan, DKI Jakarta, 12950, \\ Indonesia \\ ${ }^{\square}$ Corresponding Author: triyn102@ugm.ac.id
}

\begin{abstract}
This study evaluated the formation steps of Graphene Oxide (GO) material from graphite precursor as well as the amount of permanganate as an oxidizing agent and its effect on the character and chemical structure of produced GO. The production of GO materials with the variation in the permanganate/graphite weight ratio of $0.5,2.0$, and 3.5 was carried out using the modified improved Hummers method. Every synthesized material was analyzed using XRD, UV-Visible Spectrophotometer, FTIR, EDX, and TEM-SAED. The obtained results were GO-0.5 had not been oxidized as evidenced by the presence of two diffraction peaks similar to the graphite at $2 \theta=43.524^{\circ}$ and $26.235^{\circ}$. GO-2.0 had been partially oxidized as characterized by the appearance of three diffraction peaks at $42.489^{\circ}, 26.163^{\circ}$, and $11.522^{\circ}$. GO-3.5 had been fully oxidized successfully as represented by the presence of two typical diffraction peaks at $42.460^{\circ}$ and $10.457^{\circ}$. GO-3.5 had vibrational peaks of characteristic oxygenated carbon groups like hydroxyl, epoxy, carboxyl, and carbonyl in FTIR spectrum, likewise, it had wavelength absorption at $233 \mathrm{~nm}$ associated with the transition $\pi \rightarrow \pi^{*}$ of the $\mathrm{C}=\mathrm{C}$ bond and at around $300 \mathrm{~nm}$ related to the $\mathrm{n} \rightarrow \pi^{*}$ transition of the $\mathrm{C}=\mathrm{O}$ bond. This GO3.5 ratio can be utilized for wide-scale fabrication because it can reduce production costs. Moreover, the applied synthesis procedure was also safe (non-toxic and non-exothermic) according to green chemistry principles.

Keywords: Graphene Oxide, Graphite, Wide-scale fabrication, Modified Improved Hummers, Permanganate

RASĀYAN J. Chem., Vol. 14, No.3, 2021
\end{abstract}

\section{INTRODUCTION}

Graphene is a monolayer material consisting of only $\mathrm{sp}^{2}$ hybridized carbon atoms and packed tightly in the form of hexagonal crystal lattice ${ }^{1}$. Since the invention of graphene, there was a critical impact in various material fields because of its crucial physicochemical properties ${ }^{2}$. Hence, it has been extensively investigated for potential applications in electronics, catalysis, sensors, and energy transformation and storage, etc ${ }^{3}$. The general method to fabricate the graphene is by exfoliating its precursor, graphite ${ }^{4}$. The exfoliation of graphite precursor into graphene can be operated by a scotch tape of bulk graphite and CVD ${ }^{5}$. Even if those pathways are favored because of the products' uniformity, they will be less potent for widescale fabricating ${ }^{6}$. Subsequently, chemical strategies arise as a worthy alternative. So far, the exfoliation of graphite material has been centered fundamentally on the intercalation step and oxidation-reduction reactions ${ }^{7}$.

The utilization of intense oxidizing agents to generate graphene oxide (GO) is a highly available route of graphite exfoliation ${ }^{8}$. GO is an intermediate product generated in the conversion of graphite into a graphenelike material. Even though the precise structure of GO is complicated to confirm, but it can be assumed that there is the existence of $\mathrm{sp}^{3}$ hybridized carbon atoms in GO that are covalently bonded with oxygen functional groups ${ }^{9}$. The groups have been shown as regularly like hydroxyl and epoxy groups on the basal plane while carboxyl and carbonyl groups at the sheet edge with minor quantities ${ }^{10}$. Contrasted with pure graphene, the oxygen functionalized groups in GO can provide incredible structure defects, but the

Rasayan J. Chem., 14(3), 2129-2135(2021)

http://doi.org/10.31788/RJC.2021.1436004

This work is licensed under a CC BY 4.0 license. 
appearance of these groups can also offer power benefits for utilizing GO in many different applications ${ }^{11}$. This is due to the polar nature of the GO supplying it to be genuinely hydrophilic so that the dissolvability level of GO increases in numerous solvents, especially in water ${ }^{12}$.

The GO synthesis method was first discovered by Brodie and Staudenmaier ${ }^{13}$. The extremely significant and greatly exhausted manner for the production of GO was extended by Hummers and Offeman in $1958^{14}$. Tour and co-workers upgraded the conventional Hummers procedure by removing $\mathrm{NaNO}_{3}$, raising the total of $\mathrm{KMnO}_{4}$, and introducing the combination of $\mathrm{H}_{2} \mathrm{SO}_{4} / \mathrm{H}_{3} \mathrm{PO}_{4}(9 / 1$ by volume $)$ in the reaction system ${ }^{15}$. This modification is effective in increasing the yield and decreasing poisonous gas emision ${ }^{16}$. Recently, Ranjan and co-workers studied the synthesis of GO with appropriate option of reaction parameters, including temperature and time. A pre-cooling step is identified to oversee the explosive properties of the exceptionally exothermic reactions throughout the oxidation process ${ }^{17}$.

Potassium permanganate $\left(\mathrm{KMnO}_{4}\right)$ is one of the strongest oxidizing agents, specifically in acidic media. Using the support of $\mathrm{KMnO}_{4}$, complete intercalation of graphite in concentrated $\mathrm{H}_{2} \mathrm{SO}_{4}$ can be accomplished since there is infiltration of the oxygen functional groups into graphene sheets during oxidation $^{18}$. The suggested weight proportion of $\mathrm{KMnO}_{4}$ and graphite until now is 6:1. Nevertheless, the investigation on the amount of $\mathrm{KMnO}_{4}$ in the fabrication of $\mathrm{GO}$ is still rarely conducted. Therefore, this research aims to prepare and characterize $\mathrm{GO}$ with various $\mathrm{KMnO}_{4}$ amounts synthesized by adopting the Ranjan group's method and examine the influence of oxidizing agent enhancement towards the structure and chemical properties in the formation steps of GO. We hope from this research, there will be discoveries about the weight ratio of $\mathrm{KMnO}_{4}$ and graphite, which are lower than the recommendation, so this method will be more efficient, effective, and following the principles of green chemistry.

\section{EXPERIMENTAL}

\section{Materials}

Each synthetic applied in this procedure is from commercial resources (E-Merck Germany) and used without further purification. These materials include graphite powder, potassium permanganate $\left(\mathrm{KMnO}_{4}\right)$, sulfuric acid $\left(\mathrm{H}_{2} \mathrm{SO}_{4} 98 \%\right)$, orthophosphoric acid $\left(\mathrm{H}_{3} \mathrm{PO}_{4} 85 \%\right)$, hydrogen peroxide $\left(\mathrm{H}_{2} \mathrm{O}_{2} 30 \%\right)$, hydrochloric acid ( $\mathrm{HCl} 37 \%$ ), absolute ethanol, silver nitrate, and barium chloride. For the washing process, deionized (DI) water, bi-distilled water, and phosphate-buffered saline (PBS) are utilized.

\section{General Procedure}

Our method is adapted from the Ranjan group's method with a few modifications. First, each combination of $\mathrm{KMnO}_{4}$ and graphite in various weight ratios of $0.5 ; 2.0 ; 3.5$ were mixed and crushed in a mortar for 5 minutes. The mixture of graphite and $\mathrm{KMnO}_{4}$ was put into beaker $\mathrm{A}$ while the mixture of $\mathrm{H}_{2} \mathrm{SO}_{4}$ and $\mathrm{H}_{3} \mathrm{PO}_{4}$ in volume ratio $9 / 1$ was put into beaker $\mathrm{B}$. The two beakers are cooled below $5{ }^{\circ} \mathrm{C}$ for 6 hours. The solution in beaker B was poured into beaker A, stirred for 2 minutes until the solution was greenish-black, and heated at $65^{\circ} \mathrm{C}$ for 24 hours. After the heating time was finished, the color of the solution became brownish, the beaker was left for 30 minutes, so it reaches room temperature. Subsequently, the solution was poured into another beaker containing $500 \mathrm{~g}$ of DI water ice, added $7 \mathrm{ml} \mathrm{H}_{2} \mathrm{O}_{2}$, and stirred using a stirring rod. The color of the solution got brownish-yellow instantly, marking the formation of GO. The solution was left for one hour to precipitate the solids. The solids were washed by centrifugation at $5000 \mathrm{rpm}$ for 5 minutes using a solution of $\mathrm{HCl}$ (2 times), ethanol absolute ( 3 times), and PBS until the $\mathrm{pH}$ of the GO solution became 7. The solution was then checked for $\mathrm{Cl}^{-}$ions content using $\mathrm{AgNO}_{3}$ and $\mathrm{SO}_{4}^{2-}$ ions content using $\mathrm{BaCl}_{2}$. The solution was rewashed using bi-distilled water, so it was completely free from both of them. The obtained GO solids were dried in an oven, then characterized using XRD, FTIR, UV-Visible, EDX, and TEM-SAED.

\section{Detection Method}

X-Ray Diffraction (XRD, Bruker D2 Phaser) at a wide-angle range of 5-90 ${ }^{\circ}$ was used to determine the crystallinity of the materials. The typical functional groups of the materials were characterized by Fourier Transform Infra-Red Spectrometer (FTIR, Shimadzu Prestige 21) at 4000-400 $\mathrm{cm}^{-1}$. The element content was evaluated by Energy Dispersive X-ray (EDX, JSM-6510LA). The wavelength absorption of the materials was observed using UV-Visible Spectrophotometer (UV-Vis, UV-1800 Shimadzu) at the wavelength range of 200-800 $\mathrm{nm}$. The materials' structure morphology and polycrystalline ring images 
RASĀYAN J. Chem.

Vol. 14 | No. 3 |2129-2135| July - September | 2021

were taken using a Transmission Electron Microscope-Selected Area Electron Diffraction (TEM-SAED, JEOL JEM-1400).

\section{Analysis of X-Ray Diffraction (XRD)}

\section{RESULTS AND DISCUSSION}

The crystallinity and phase purity of each material were investigated by XRD. The diffractograms exhibit typical diffraction peaks of graphite and GO, as shown in Fig.-1. Graphite as a raw material for GO production reveals a very sharp and strong diffraction peak at $26.213^{\circ}$ (hkl plane of 002) and a very weak peak at $42.327^{\circ}(\mathrm{hkl} \text { plane of } 100)^{19}$. These peaks are under ICDD data of 01-075-1621. The peak of 002 was used to observe the change of graphite to GO because it indicates $\mathrm{sp}^{2}$ hybridized carbon bonds in a stacked structure. The diffraction peak of the 002 shifts to a smaller $2 \theta$ around $10-11^{\circ}$, and its intensity decreases when the amount of permanganate is added to graphite. GO- 0.5 shows the diffraction peaks, which are still similar to graphite. This is due to the addition of the small amount of permanganate as an oxidizing agent, so it has not been able to oxidize graphite material into GO. Nevertheless, the diffraction peak intensity at $26.235^{\circ}$ decreases since the crystal defects arise from the existence of oxygen functional groups during the oxidation process. Furthermore, GO-2.0 has three diffraction peaks, including $42.489^{\circ}$, $26.163^{\circ}$, and $11.522^{\circ}$. Over the addition of more permanganate, the oxidation process was rather successfully carried out as evidenced by a diffraction peak that appears at around $11^{\circ}$ as a characteristic of the effectual formation of GO material. There is still a peak at $\sim 26^{\circ}$ indicates that the $\mathrm{sp}^{2}$ conjugated carbon dominates in this material, although in a lower intensity than GO-0.5. This change happens to the heterogeneous character involving the $\mathrm{sp}^{2}$ domain of pure graphite and the $\mathrm{sp}^{3}$ domain of oxidized graphite. Therefore, this material has more graphitic and fewer oxidized domains because the intensity of the peak at $\sim 26^{\circ}$ is much higher than the peak at $\sim 11^{\circ}$. This states that the oxidation process was still incomplete or mentioned as partial oxidation because the added permanganate is not strong enough to fully oxidize the graphite into GO material. On GO-3.5, there is no peak at $\sim 26^{\circ}$, but instead, a peak with high intensity is observed at $10.457^{\circ}$. This spectrum concludes that the complete oxidation process in GO can be achieved by adding a permanganate proportion to the graphite of 3.5. Consequently, the presence of oxygen functionalized groups is effectively entered among the graphene layers so that the distance between the layers gets wider than before ${ }^{20}$. This also represents that the formation of GO material has been successfully investigated.

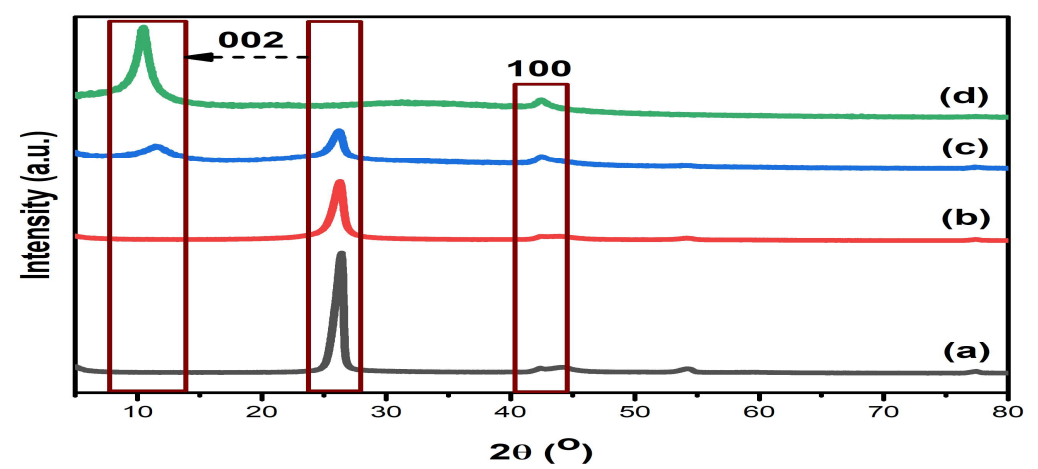

Fig.-1: XRD Spectra of (a) Graphite, (b) GO-0.5, (c) GO-2.0, (d) GO-3.5

Table-1: XRD Spectra Analysis Data of Graphite and GO

\begin{tabular}{c|c|c|c|c|c|c|c|c|c|c}
\hline \multirow{2}{*}{ No } & \multirow{2}{*}{ Material } & \multicolumn{3}{|c|}{ Peak (100) } & \multicolumn{5}{|c|}{ Peak (002) } \\
\cline { 3 - 12 } & & $2 \theta\left(^{\circ}\right)$ & $\begin{array}{c}\mathrm{d} \\
(\mathrm{nm})\end{array}$ & FWHM & $\mathrm{D}(\mathrm{nm})$ & $2 \theta\left(^{\circ}\right)$ & $\begin{array}{c}\mathrm{d} \\
(\mathrm{nm})\end{array}$ & FWHM & $\mathrm{H}(\mathrm{nm})$ & $\mathrm{n}$ \\
\hline 1 & Graphite & 42.327 & 0.213 & 0.458 & 38.027 & 26.213 & 0.340 & 0.744 & 10.963 & 32 \\
\hline 2 & GO-0.5 & 43.524 & 0.208 & 2.936 & 5.956 & 26.235 & 0.340 & 0.938 & 8.696 & 26 \\
\hline 3 & GO-2.0 & 42.489 & 0.213 & 1.555 & 11.206 & 26.163 & 0.340 & 1.061 & 7.687 & $23-24$ \\
\hline & & & & & & 11.522 & 0.767 & 2.086 & 3.828 & $5-6$ \\
\hline 4 & GO-3.5 & 42.460 & 0.213 & 0.907 & 19.211 & 10.457 & 0.845 & 1.134 & 7.035 & $8-9$ \\
\hline
\end{tabular}

Based on Table-1, the Bragg equation is applied to estimate the distance between the graphene sheets for (002) reflection, expressed as the $\mathrm{d}$ symbol. Meanwhile, the constants of 0.9 and 1.84 (Warren constant) 
are utilized successively in the Scherrer equation to calculate the average height of the stacking layer $(\mathrm{H})$ for (002) reflection and the average diameter of the stacking layer (D) for (100) reflection. Graphite, GO-0.5, GO-2.0, and GO-3.5 have the dimension size of stacking nanostructure of $38 \times 11,6 \times 9,11 \times 8$ as well as $11 \times 4$, and $19 \times 7 \mathrm{~nm}$, respectively, with increasing d spacing from 0.34 to approximately $0.7-0.8 \mathrm{~nm}$. By this $\mathrm{H} / \mathrm{d}$ value, the number of layers (n) that resulted in the nanostructure also decreases from 32 to 8-9, indicating the graphite exfoliation process has been successfully executed. From these numbers, it can be deduced that when more permanganate is enhanced, so the diffraction peaks will shift to the smaller $2 \theta$, the distance between the graphene layers is also wider, and the number of graphene layers produced will be less. This is following previous studies from Stobinski et al. ${ }^{21}$.

\section{Analysis of Fourier -Transform Infra-Red (FTIR) Spectrophotometry}

Figure-2 represents the specific functional groups of Graphite and GO. Both materials display the vibration absorption at $\sim 3400 \mathrm{~cm}^{-1}$ originating from the appearance of adsorbed water molecules and structural O-H groups $^{22}$. Moreover, all GO materials show an absorption band at $\sim 2800 \mathrm{~cm}^{-1}$ which referred to the C-H stretching vibration of the $\mathrm{CH}_{2}$ groups, a band at $\sim 1700 \mathrm{~cm}^{-1}$ which corresponds to the stretching of $\mathrm{C}=\mathrm{O}$ (carbonyl) from $\mathrm{COOH}$ and ketone groups located at the edge. Afterward, the bands at $1100-1200 \mathrm{~cm}^{-1}$ and around $\sim 1000 \mathrm{~cm}^{-1}$ confirmed to $\mathrm{C}-\mathrm{O}$ vibration from epoxy and $\mathrm{COOH}$ (carboxyl) as well as alcohol successively. These are the typical groups that lead to an increase in the distance between the graphene layers in $\mathrm{GO}$, as described in the previous XRD analysis. The presence of $\mathrm{C}=\mathrm{C}$ vibration at $1500-1600 \mathrm{~cm}^{-}$ ${ }^{1}$ reflects the aromatic areas that are not oxidized ${ }^{23}$. The outcomes of this examination are following the prior investigation by Shao et al. $(2012)^{24}$. The above-observed spectra show that the higher the oxidation level, the sharper peak absorption of oxygen functional groups. Detailed data on wavenumber absorption of each material is provided in Table- 2 .

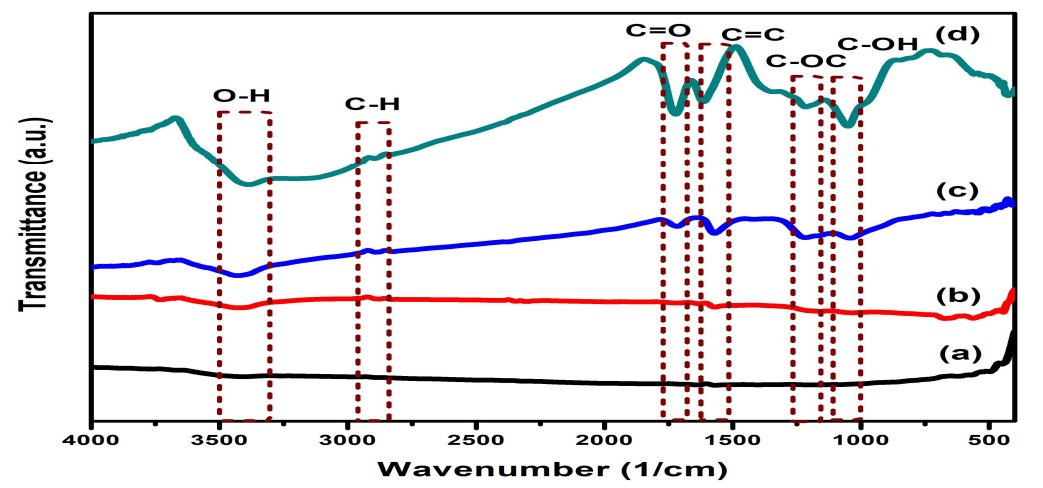

Fig.-2: FTIR Spectra of (a) Graphite, (b) GO-0.5, (c) GO-2.0, (d) GO-3.5

Table-2: Wavenumber Absorptions of Graphite and GO

\begin{tabular}{c|c|c|c|c|c|c|c}
\hline \multirow{2}{*}{ No. } & \multirow{2}{*}{ Material } & \multicolumn{7}{|c}{ Bond Type } \\
\cline { 3 - 8 } & & $\mathrm{O}-\mathrm{H}$ & $\mathrm{C}-\mathrm{H}$ & $\mathrm{C}=\mathrm{O}$ & $\mathrm{C}=\mathrm{C}$ & $\mathrm{C}-\mathrm{OC}$ & $\mathrm{C}-\mathrm{OH}$ \\
\hline 1 & Graphite & 3402.58 & - & - & - & - & - \\
\hline 2 & GO-0.5 & 3148.97 & 2876.95 & 1732.15 & 1568.19 & 1159.27 & 1029.07 \\
\hline 3 & GO-2.0 & 3425.72 & 2892.38 & 1716.72 & 1571.09 & 1216.17 & 1040.64 \\
\hline 4 & GO-3.5 & 3386.18 & 2896.24 & 1720.58 & 1613.52 & 1214.24 & 1051.25 \\
\hline
\end{tabular}

Analysis of UV-Visible Spectrophotometry

Figure-3 is UV-Visible spectra from the aqueous dispersion of each GO material. The spectra of GO-0.5 and GO-2.0 do not show any absorption peaks that indicating the materials have not been successfully synthesized. In Contrastly, the GO-3.5 spectrum has a prominent absorption peak at a wavelength of 233 $\mathrm{nm}$ accompanied by a shoulder peak at around $300 \mathrm{~nm}$, which is related to the transition $\pi \rightarrow \pi^{*}$ of the aromatic carbon bond and the transition $n \rightarrow \pi^{*}$ of the carbonyl bond successively. This absorption is identical to the GO sample reported by Chen et al. $(2013)^{15}$. The GO dispersion also exhibits a brownish yellow color which reveals that the oxidation process successfully forms GO. Meanwhile, the GO-0.5 and 
GO-2.0 dispersion show a blackish grey color. Graphite disperses cannot be measured with a UV-Visible spectrophotometer because the nature of graphite is non-polar material, so it does not dissolve in water as a solvent. Subsequently, the presence of oxygen functional groups in GO as displayed in FTIR data can enhance the polarity of graphite material because it has a part of $\mathrm{sp}^{3}$ carbon hybridization.

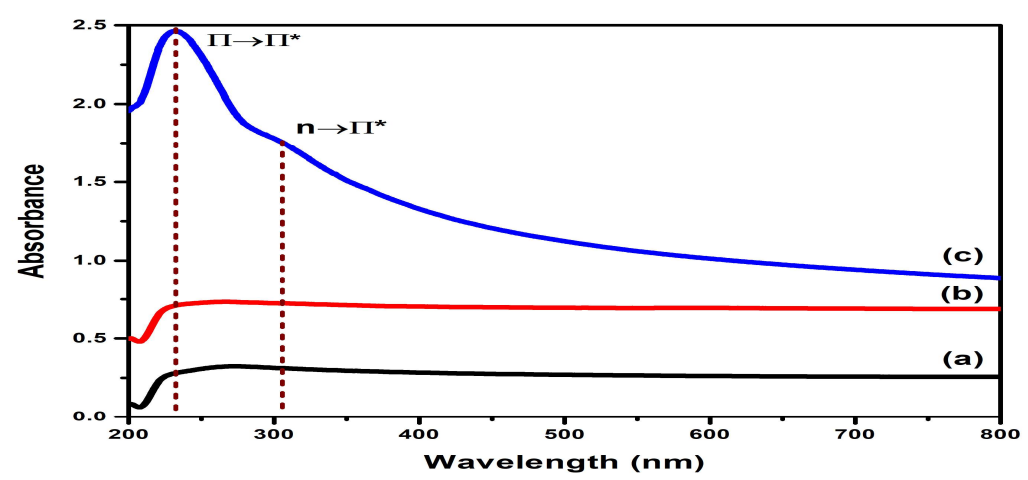

Fig.-3: UV-Vis Spectra of (a) GO-0.5, (b) GO-2.0, (c) GO-3.5

\section{Analysis of Transmission Electron Microscope-Selected Area Electron Diffraction (TEM-SAED)}

The plane morphology of graphite and GO prepared with various quantities of permanganate was taken using TEM, as shown in Fig.-4. Each material has layers with slightly different translucent. This is possible because the total layers in the graphite and GO are also dissimilar, as proven by the calculation result of XRD data. TEM images contain dark and bright areas. Dark areas represent stacked layers, while bright areas denote exfoliated layers. Graphite shows the stacked layers resulting in most parts of the image are not transparent. GO-0.5 and GO2.0 display the morphology that consisted of many partially oxidized graphite layers. These materials contain less oxygenated functional groups that restrict exfoliating into a single layer or a few layers after the peeling off stage, so it looks less transparent. Meanwhile, GO-3.5 seems almost transparent because this material has more amount of oxygen functionalized groups which compatible with exfoliation or intercalation. Nevertheless, it was concluded that these images generally do have not significantly different layer morphology and transparency.

The SAED is utilized to assign the polycrystalline properties of nanoscale material. In Fig.-5, it is observed that the SAED pattern has a distinct diffraction ring that appropriates with diverse oxidation conditions. Graphite and GO-0.5 exhibit a ring representing the polycrystalline property of the material. This pattern comes from the integration of freckles diffraction because of the escalating number of layers in the material. GO-2.0 shows an unclear ring pattern which denotes that GO has amorphous property.
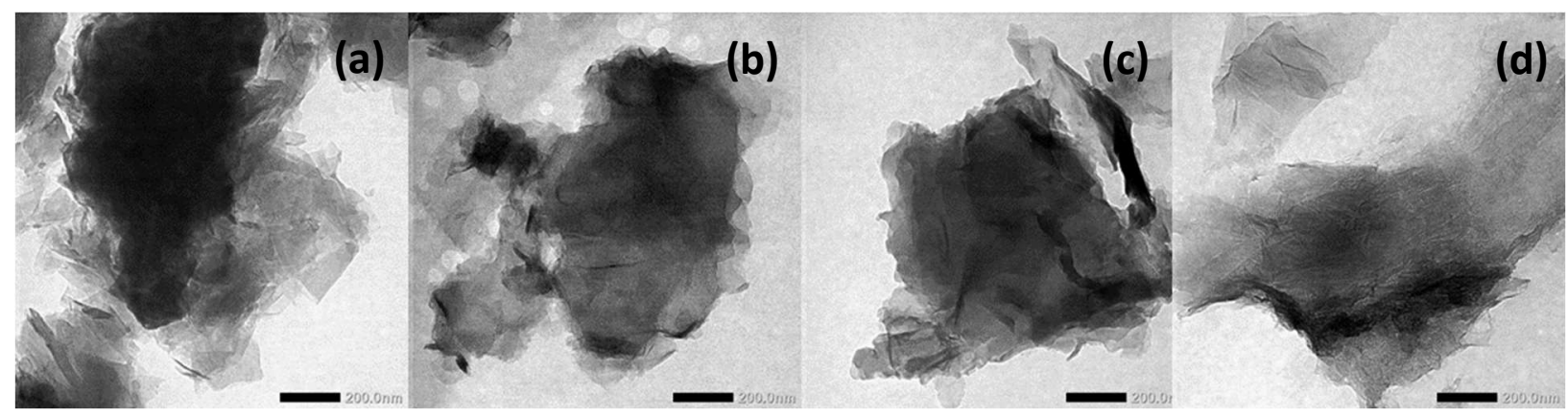

Fig.-4 TEM Images of (a) Graphite, (b) GO-0.5, (c) GO-2.0, (d) GO-3.5

The amorphous area in GO happens because of the availability of several $\mathrm{sp}^{3}$ hybridized carbon formed throughout the oxidation process. Nevertheless, the GO-3.5 ring pattern reappears rather clearly. We deduce that $\mathrm{GO}$ is composed entirely of amorphous areas, but some crystal regions also exist. Some reports declared about the presence of non-oxidized domains ( $\mathrm{sp}^{2}$ content) in oxidized domains ( $\mathrm{sp}^{3}$ content) on GO. This indicates that the oxygenated functional groups in the graphite grid do not generate the conformation of every type of superlattice ordered array. The TEM results from the GO samples are in good agreement with the previous study from Krishnamoorthy et al. (2013). ${ }^{25}$ 


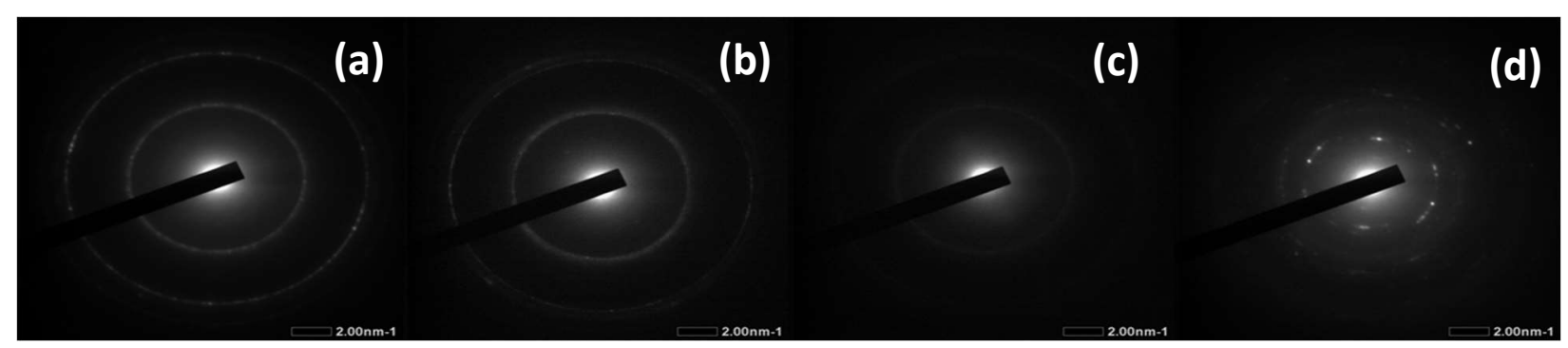

Fig.-5: SAED Pattern of (a) Graphite, (b) GO-0.5, (c) GO-2.0, (d) GO-3.5

Based on calculations on the SAED pattern on each material, the data can be seen in Table-3. It can be assumed that the higher the oxidation level, the wider $d$ spacing in the crystal plane of 002 due to the presence of oxygen functional groups among graphene sheets. This reinforces the argumentation on the XRD data, where GO-3.5 was proven to be successfully synthesized, indicated by the increase in the distance between graphene layers from 0.3 to $0.6 \mathrm{~nm}$.

Table-3: SAED Pattern Analysis of Graphite and GO

\begin{tabular}{c|c|c|c}
\hline No & Materials & $\mathrm{d}(\mathrm{nm}) 002$ & $\mathrm{~d}(\mathrm{~nm}) 100$ \\
\hline 1 & Graphite & 0.302 & 0.156 \\
\hline 2 & GO-0.5 & 0.317 & 0.152 \\
\hline 3 & GO-2.0 & 0.317 & 0.136 \\
\hline 4 & GO-3.5 & 0.609 & 0.219 \\
\hline
\end{tabular}

Analysis of Energy Dispersive X-Ray (EDX) Spectroscopy

EDX analysis presents the mass percentage of carbon and oxygen elements contained in each material which is presented in Table-4. Graphite precursor consists of $100 \%$ carbon element. After the graphite is treated with the addition of an oxidizing agent, the \%mass of carbon decreases while the \%mass of oxygen appears. The amount of oxygen increases along with the amount of oxidizing agent used in GO synthesis. The $\mathrm{C} / \mathrm{O}$ ratio represents the level of oxidation, where the lower ratio indicates the higher level of oxidation. These data confirm the reasons for the successful formation of GO-3.5 in the previous data including XRD, FTIR, and UV-Vis spectra.

Table-4: Elemental Content in Graphite and GO

\begin{tabular}{c|l|c|c|c}
\hline No & Material & \%Mass C & \%Mass O & Ratio C/O \\
\hline 1 & Graphite & 100 & 0 & $\sim$ \\
\hline 2 & GO-0.5 & 91.75 & 8.25 & 11.12 \\
\hline 3 & GO-2.0 & 89.46 & 10.54 & 8.49 \\
\hline 4 & GO-3.5 & 65.21 & 34.79 & 1.87 \\
\hline
\end{tabular}

CONCLUSION

The study of graphene oxide (GO) formation with the various weight ratio of permanganate to the graphite of $0.5,2.0$, and 3.5 has been successfully carried out. Each GO has a different chemical character and structure corresponding to the given oxidation level. GO-0.5 has not been successfully oxidized, GO-2.0 has been partially oxidized, and GO-3.5 has been fully oxidized. Therefore, this ratio of 3.5 can be utilized for large-scale fabrication considering the recommended ratio in GO synthesis until now is 6 . This new suggestion can minimize production costs and fulfill green chemistry principles because the synthesis process applied is safe.

\section{ACKNOWLEDGMENT}

The authors thank the Ministry of Research, Technology, and Higher Education, Republic of Indonesia, for the fund through the PMDSU Research Grant 2019 (Contract number: 6318/UN1.DITLIT/DITLIT/LT/2019) and also Universitas Gadjah Mada for the financial support of this work under the scheme of the Rekognisi Tugas Akhir (RTA) 2020.

\section{REFERENCES}

1. R. Yadav, A. Subhash, N. Chemmenchery, and B. Kandasubramanian, Industrial \& Engineering Chemistry Research, 57, 9333(2018), https://doi.org/10.1021/acs.iecr.8b02326 
RASĀYAN J. Chem.

Vol. 14 | No. 3 |2129-2135| July - September | 2021

2. P. Avouris, C. Dimitrakopoulos, Materials Today, 15(3), 86(2012), https://doi.org/10.1016/S1369-7021(12)70044-5

3. AK Sahu, K. Ketpang, S. Shanmugam, O. Kwon, S. Lee, and H. Kim, The Journal of Physical Chemistry C, 120, 15855(2016), https://doi.org/10.1021/acs.jpcc.5b11674

4. M.S.A. Bhuyan, M.N. Uddin, M.M. Islam, F.A. Bipasha, and S.S. Hossain, International Nano Letters, 6, 65(2016), https://doi.org/10.1007/s40089-015-0176-1

5. M. Liu, R. Zhang, and W. Chen, Chemical Reviews, 114, 5117(2014), https://doi.org/10.1021/cr400523y

6. T.F. Emiru, D.W. Ayele, Egyptian Journal of Basic and Applied Sciences, 4, 74(2017), https://doi.org/10.1016/j.ejbas.2016.11.002

7. M. Khan, M.N. Tahir, S.F. Adil, H.U. Khan, M.R.H. Siddiqui, A.A. Al-warthan, and W. Tremel, Journal of Materials Chemistry A, 3, 18753(2015), https://doi.org/10.1039/c5ta02240a

8. V. Skakalova, P. Kotrusz, M. Jergel, T. Susi, A. Mittelberger, V. Vretenar, P. Siffalovic, J. Kotakoski, J.C. Meyer, and M. Hulman, The Journal of Physical Chemistry C, 122(1), 929(2017), https://doi.org/10.1021/acs.jpcc.7b10912

9. M. Lojka, B. Lochman, O. Jankovsky, A. Jirickova, Z. Sofer, and D. Sedmidubsky, Materials, 12, 2367(2019), https://doi.org/10.3390/ma12152367

10. D.R. Chowdhury, C. Singh, and A. Paul, RSC Advances, 4, 15138(2014), https://doi.org/10.1039/c4ra01019a

11. A.T. Smith, A.M. LaChance, S. Zeng, B. Liu, L. Sun, Nano Materials Science, 1(1), 31(2019), https://doi.org/10.1016/j.nanoms.2019.02.004

12. D. Chen, H. Feng, and J. Li, Chemical Reviews, 112, 6027(2012), https://doi.org/10.1021/cr3001115g

13. S.K. Tiwari, R.K. Mishra, S.K. Ha, and A. Huczko, Carbon Nanomaterials, 4, 598(2018), https://doi.org/10.1002/cnma.201800089

14. M. Sohail, M. Saleem, S. Ullah, N. Saeed, A. Afridi, M. Khan, M. Arif, Modern Electronic Materials, 3, 110(2017), https://doi.org/10.1016/j.moem.2017.07.002

15. J. Chen, B. Yao, C. Li, G. Shi, Carbon, 64, 225(2013), https://doi.org/10.1016/j.carbon.2013.07.055

16. D.C. Marcano, D.V. Kosynkin, J.M. Berlin, A. Sinitskii, Z. Sun, A. Slesarev, L.B. Alemay, W. Lu, and JM Tour, ACS Nano, 4(8), 4806(2010), https://doi.org/10.1021/nn1006368

17. P. Ranjan, S. Agrawal, A. Sinha, R. Rao, J. Balakrishnan, and A.D. Thakur, Scientific Reports, 8, 12007(2018), https://doi.org/10.1038/s41598-018-30613-4

18. V. Purwandari, S. Gea, B. Wirjosenntoso, A. Haryono, S. rahayu, and Y.A. Hutapea, Rasayan Journal of Chemistry, 13(1), 593(2020), https://doi.org/10.31788/RJC.2020.1315473

19. V. Sivasankar, E.S. Kumar, R.S. Babu, S. Raghu, and R.A. Kalaivani, Rasayan Journal of Chemistry, 10(4), 1232(2017), https://doi.org/10.7324/RJC.2017.1041749

20. D. Ratih, R. Siburian, and Andriayani, Rasayan Journal of Chemistry, 11(4), 1649(2018), https://doi.org/10.31788/RJC.2018.1145007

21. L. Stobinski, B. Lesiak, A. Malolepszy, M. Mazurkiewicz, B. Mierzwa, J. Zemek, P. Jiricek, I. Bieloshapka, Journal of Electron Spectroscopy and Related Phenomena, 195, 145(2014), https://doi.org/10.1016/j.elspec.2014.07.003

22. T. Kamakshi, GS Sundari, H. Erothu, and T.P. Rao, Rasayan Journal of Chemistry, 11(3), 1113(2018), https://doi.org/10.31788/RJC.2018.1134003

23. R. Aarthi and K.C. Lalithambika, Rasayan Journal of Chemistry, 7(4), 340(2014)

24. G. Shao, Y. Lu, F. Wu, C. Yang, F. Zeng, Q. Wu, Journal of Materials Science, 47, 4400(2012), https://doi.org/10.1007/s10853-012-6294-5

25. K. Krishnamoorthy, M. Veerapandian, K. Yun, S.-J. Kim, Carbon, 53, 38(2013), https://doi.org/10.1016/j.carbon.2012.10.013

[RJC-6004/2020] 